\title{
Intersensory conflict between vision and touch: The response modality dominates when precise, attention-riveting judgments are required
}

\author{
MORTON A. HELLER \\ Winston-Salem State University, Winston-Salem, North Carolina \\ JEFFREY A. CALCATERRA \\ Wright State University, Dayton, Ohio \\ and \\ SHAVONDA L. GREEN and LATONYA BROWN \\ Winston-Salem State University, Winston-Salem, North Carolina
}

\begin{abstract}
In four experiments, reducing lenses were used to minify vision and generate intersensory size conflicts between vision and touch. Subjects made size judgments, using either visual matching or haptic matching. In visual matching, the subjects chose from a set of visible squares that progressively increased in size. In haptic matching, the subjects selected matches from an array of tangible wooden squares. In Experiment 1, it was found that neither sense dominated when subjects exposed to an intersensory discrepancy made their size estimates by using either visual matching or haptic matching. Size judgments were nearly identical for conflict subjects making visual or haptic matches. Thus, matching modality did not matter in Experiment 1. In Experiment 2, it was found that subjects were influenced by the sight of their hands, which led to increases in the magnitude of their size judgments. Sight of the hands produced more accurate judgments, with subjects being better able to compensate for the illusory effects of the reducing lens. In two additional experiments, it was found that when more precise judgments were required and subjects had to generate their own size estimates, the response modality dominated. Thus, vision dominated in Experiment 3, where size judgments derived from viewing a metric ruler, whereas touch dominated in Experiment 4, where subjects made size estimates with a pincers posture of their hands. It is suggested that matching procedures are inadequate for assessing intersensory dominance relations. These results qualify the position (Hershberger \& Misceo, 1996) that the modality of size estimates influences the resolution of intersensory conflicts. Only when required to self-generate more precise judgments did subjects rely on one sense, either vision or touch. Thus, task and attentional requirements influence dominance relations, and vision does not invariably prevail over touch.
\end{abstract}

Researchers have long found that vision is dominant over other modalities when conflicting information is presented (e.g., Ryan, 1940, p. 687). Rock and his colleagues reported an influential series of experiments demonstrating visual dominance, given a conflict between the

Preparation of this report and some of the research were supported by NIH Grant 2 SO6 RR-08040. Faith Heller provided helpful comments on an earlier version of this manuscript. Cindy Flynt assisted with data collection and analyses. We are grateful to Richard Williams for advice about optics and optical measurements on the lens used in Experiments 1 and 2. Lester Krueger, Mark Hollins, and two anonymous reviewers made helpful comments on this manuscript. Correspondence concerning this article should be addressed to M. A. Heller, Department of Psychology, Eastern Illinois University, 119 Physical Science Bldg., 600 Lincoln Avenue, Charleston, IL 61920-3099 (e-mail: cfmahl@eiu.edu).

-Accepted by previous editor, Myron L. Braunstein sense of vision and the sense of touch (Rock \& Harris, 1967; Rock \& Victor, 1964). The subjects in Rock's experiments felt a square through a cloth while looking at it through a reducing lens, which minifies vision, and made a single judgment about the size (or shape) of the stimulus object. Rock reported that subjects generally relied on vision for their judgments, despite the fact that this yielded nonveridical perception. These experiments have been influential; they have prompted a great deal of research and have convinced many people that vision is invariably dominant over touch.

The visual dominance literature has relied heavily on the discrepancy paradigm introduced by Rock and Victor (1964), which presupposes that subjects will assume that they are feeling and seeing the same object. There is no real conflict between vision and touch if we look at one object and feel another. Rock and Victor used a variety of response measures in their study. Their subjects showed visual dom- 
inance when making haptic matches, when drawing the stimuli using sight, and when making visual matches.

The Rock and Victor (1964) discrepancy paradigm makes the assumption that subjects will have no difficulty making accurate judgments about length with both vision and touch. However, things are not that simple, and there are a number of reasons to doubt that subjects can make comparably accurate simultaneous or sequential comparisons through both modalities (see Freides, 1974, 1975). There are reports indicating that conditions of delay can influence haptic or cross-modal conditions more than they influence visual judgments (Abravanel, 1973; Cashdan, 1968; Cashdan \& Zung, 1970; Zung, Butter, \& Cashdan, 1974). Thus, memory demands could affect resolution of conflicts between vision and touch, because the Rock and Harris (1967) discrepancy paradigm forces subjects to remember the stimulus experienced during the conflict trial. It is very possible that the results are limited to differential memory skills for the senses of vision and touch. Other studies indicate that subjects have difficulty making size estimates with touch. Bartley (1953) assumed that tactual judgments were generally modified by visual imagery and, also, that visual judgments of size were influenced by true distance. Schlater, Baker, and Wapner (1981) reported that perceived arm length was different when subjects were active or passive and actually shrank when subjects were passively touched. These reports conflict with recent empirical evidence that suggests that people are able to make veridical, equivalent judgments of length with vision and touch (Abravanel, 1971; Teghtsoonian \& Teghtsoonian, 1970).

Recently, Power (1981) verified many of Rock's (Rock \& Harris, 1967; Rock \& Victor, 1964) findings and found that visual dominance occurs with a familiar objectnamely, a coin. Furthermore, the phenomenon of visual dominance seemed robust, since it even occurred with the bare hand. However, a strong lens tended to reduce the reliance on vision when the bare hand was visible (Power, 1980). Power used a lens that distorted the shape of visible objects, causing a square to appear rectangular. It is possible that this distortion was responsible for a shift in apparent reliance on the senses of vision and touch.

There are limits to visual dominance. It is not evident with texture perception (Heller, 1982, 1989; Lederman \& Abbott, 1981) or when vision is blurry (Heller, 1983). Also, haptic dominance can occur in pattern perception when vision is manipulated by a mirror, rather than by a lens (Heller, 1992). The results of these studies suggest that visual dominance may not be found when vision is used for the guidance of hand movements and subjects can see their hands explore objects or surfaces. The present experiments were designed to test dominance relations while sight of the hand was available.

Visual dominance is not invariant, and it is not the norm outside of the laboratory. It results from contriving atypical and artificial circumstances in which the confidence of subjects in touch is diminished (e.g., from feeling objects from underneath through a cloth and hiding sight of the hand) and in which the attentional capacity of touch in matching procedures is overloaded. Under many normal circumstances, people see their hands as they feel objects (Heller, 1993) and this visual information may be critical for the resolution of intersensory discrepancies. Thus, if subjects see their hands move in a direction that is counter to proprioception, most do not believe vision (Heller, 1992).

\section{Hershberger and Misceo's (1996) Study}

A recent, interesting report by Hershberger and Misceo (1996) is clearly relevant to the present issue. Hershberger and Misceo used a variant of Rock and Victor's (1964) paradigm and had subjects feel a square while viewing it through a negative meniscus lens that halved the size of the visual image. They reported that their subjects resolved the conflict between vision and touch in favor of touch, in haptic matching conditions. When visual matches were required, the subjects showed visual dominance. When the data were examined on the first trial block, mean matching size varied with modality of the match in discrepancy conditions (see Hershberger \& Misceo, 1996, Figure 2). Subjects making visual matches in conflict conditions judged the stimuli to be slightly less than $3.5 \mathrm{~cm}$ (see Figure 2 in Hershberger \& Misceo, 1996). Visual controls (intramodal, vision alone, with vision of the standard stimuli through a reducing lens) judged the stimuli to be less than $2.5 \mathrm{~cm}$. Note that, in the intersensory conflict literature, the term control refers to conditions in which there is no conflict. Conflict judgments with haptic matching ( $M$ greater than $4 \mathrm{~cm}$ ) were closer to the mean haptic control (haptic standards and haptic matches) judgments ( $M$ slightly greater than $4.5 \mathrm{~cm}$; see Figure 2 in Hershberger \& Misceo, 1996).

Also, in conflict conditions, subjects felt the squares $\left(4,4.5,5,5.5\right.$, and $\left.6 \mathrm{~cm}^{2}\right)$ through an intervening cloth. Hershberger and Misceo (1996) assumed that the presence of the cloth made it impossible for subjects to see their hands. However, one can readily see the movement of one's fingers through an intervening opaque cloth, since motions of the cloth are visible (Heller, 1983). Conceivably, individuals are then able to perceive a reduction in finger span, using sight. If so, it is possible that changes in perceived size over trial block could reflect the influence of this knowledge of minification, acquired through vision, rather than the possible influence of haptics on resolution of the conflict. This possibility was examined in Experiment 2 of the present study.

Hershberger and Misceo (1996) reported substantial effects of trial number in their experiments, but it is not known whether adaptation effects took place over trial blocks. Thus, the subjects could have adapted to the lens, and it could have been less effective over trials. On this interpretation of their data, the apparent increase in haptic potency could have derived from visual adaptation over trial block and not from the strengthening of touch. They did report that most of their visual matching subjects showed visual dominance on the first trial, whereas a compromise between vision and touch was obtained for subjects making haptic matches (Hershberger \& Mis- 
ceo, 1996, p. 1129). Furthermore, stimuli were repeated over trial blocks, because Hershberger and Misceo wanted "to encourage the observers to notice the discordant haptic information" (p. 1127).

Hershberger and Misceo (1996) used sequential matching procedures, and that prompted the present study. Their subjects were required to remember the discrepancy stimulus before making their visual or haptic match, and their results could depend on differential retention in the two modalities of vision and touch. The researchers may have adopted the use of a delay in order to avoid biasing subjects toward touch, since in visual matching, subjects cannot simultaneously look down through a viewing tube and look up at a visual matching array. However, imposition of a delay would make it impossible to equate time intervals between conflict and matching for visual matching and haptic matching, if only because of the much slower processing times for touch (see Freides, 1974). Their subjects were exposed to a memory task for touch, as well as for vision, but there was less of a retention problem for vision, since subjects could simultaneously see all of the choices in the matching array. In the present experiments, the subjects were always simultaneously exposed to vision and to touch in conflict conditions. However, their size estimation responses never involved a load on memory for either modality. Matching was simultaneous for haptic matches in Experiment 1, and nearly so for visual matching.

The present study was designed to gather further information about the resolution of intersensory conflicts when subjects were exposed to a discrepancy between vision and touch, initially and over repeated trials. Prior research has shown that visual dominance is not a routine outcome when intersensory conflicts are resolved. Subjects may adopt judgments with no dominance or show the biasing effects of a matching modality (see Hershberger \& Misceo, 1996). In addition, much earlier research interposed a cloth between the subjects' hands and the objects they felt, and this could have reduced the subjects' confidence in the sense of touch. The present research was motivated by doubts about the adequacy of matching methods, since they typically force subjects to rely on memory and there could be modality differences in memory. Therefore, the present experiments did not impose a memory demand on vision or touch, and subjects had sight of their fingers as they touched the standard stimulus squares beneath them.

In Experiment 1, a replication of earlier research was attempted, and subjects were exposed to a discrepancy between visually perceived and haptically perceived size, but with no memory load. In Experiment 2, the influence of sight of the hand and of prior knowledge about the presence of a lens on size judgments in vision was examined. In Experiment 3, a conflict between vision and touch was presented, but subjects were required to make absolute size judgments by looking at a metric ruler. This experiment allowed finer grained size estimates than are possible with matching judgments. Conflict subjects in Experiment 4 estimated size with a pincers posture of the thumb and index finger (see Heller \& Joyner, 1993). It was thought that the use of alternative size judgment procedures with no memory load, as in the present experiments, would allow clarification of the effect of mode of response and task demands on dominance relations between vision and touch.

Hershberger and Misceo (1996) used a negative meniscus lens, and the large curvature and thickness of the lens surface could induce readily seen reflections, linear distortion, and other optical defects. Optical defects were largely eliminated in the present study by the use of a stop (an aperture smaller than the lens diameter) and by the selection of much thinner, plano-concave and doubleconcave lenses. The surface of the lens was cleaned with compressed air before each subject was tested. These precautions made it far less likely that subjects would become aware of the presence of the reducing lens.

\section{EXPERIMENT 1 Intersensory Size Conflict With No Memory Load}

The purpose of this experiment was to present an intersensory size discrepancy between vision and touch, but to eliminate memory requirements. The subjects simultaneously touched and viewed standard squares with sides of 4,5 , and $6 \mathrm{~cm}$. They were required to make visual or haptic matches to the standards. Control groups of subjects made intramodal visual matches to visually presented squares (magnification $=0.448, \mathrm{v}^{*} \mathrm{~V}$ ), or haptic matches to haptically presented squares $\left({ }^{*} \mathrm{H}-\mathrm{H}\right)$. Lowercase $\mathrm{v}$ is used here to refer to conditions with minified vision; uppercase $V$ refers to normal vision. In addition, ${ }^{*}$ represents the missing conflict condition and identifies control conditions. The term before the dash represents the stimulus, whereas the term after the hyphen represents the response.

It was not clear whether the subjects in conflict conditions ( $\mathrm{vH}-\mathrm{V} \& \mathrm{vH}-\mathrm{H}$ ) would show reliance on vision or on touch during initial presentations of the standards or on subsequent trials. Prior research has yielded visual dominance (Rock \& Victor, 1964), visual or haptic dominance, depending on the response modality (Hershberger $\&$ Misceo, 1996), haptic dominance with blurred vision (Heller, 1983), and haptic dominance, given sightof-hand movements (Heller, 1992).

\section{Method}

Subjects. Forty Winston-Salem State University undergraduates (10 in each group) participated for course credit. New subjects were used in each experiment reported here, and all the subjects were nave. Two control groups made intramodal visual $\left(\mathrm{v}^{*}-\mathrm{V}\right)$ or haptic $\left({ }^{*} \mathrm{H}-\mathrm{H}\right)$ judgments and had 4 males and 6 females in each group. As indicated by writing preference, all of the $v^{*} V$ subjects were right-handed, and 8 of the ${ }^{*} \mathrm{H}-\mathrm{H}$ subjects were right-handed ( 1 was left-handed, 1 was self-identified as ambidextrous). The conflict 
group making haptic matches $(\mathrm{vH}-\mathrm{H})$ had 5 males and 5 females, 7 of the subjects were right-handed, and 3 were left-handed; the conflict group making visual matches $(\mathrm{vH}-\mathrm{V})$ had 4 males and 6 females, 9 subjects were right-handed, and 1 was left-handed. The subjects who wore glasses or contact lenses were asked to wear them for all of the experiments reported here.

Stimuli and Apparatus. The standard stimuli consisted of 6.5mm-thick wooden squares with blue paper glued to their top surfaces. The 4-, 5-, and 6-cm squares were mounted on top of white mat board $(17.5 \times 19.5 \mathrm{~cm})$ and placed within an examination box with the dimensions of $20.5 \mathrm{~cm}$ high $\times 14 \mathrm{~cm}$ wide $\times 20 \mathrm{~cm}$ long on the inside and with a small slot on the bottom rear that allowed the experimenter to insert and remove stimuli (see Figure 1). The inside of the box was covered with white paper. There was an opening in the large foam board front panel, which allowed the subjects to reach in and feel the squares beneath their hands while they viewed them through a reducing lens mounted under the end of a viewing tube mounted on the top of the apparatus. Thus, the subjects could see the tops of their fingers and the blue squares while they felt the squares underneath them.

The 51-mm-diameter plano-concave lens was mounted with its flat surface facing up, to make it unlikely that the subjects would notice reflections induced by lens curvature. The lens was $6 \mathrm{~mm}$ thick at the edge and had a focal length of $16.2 \mathrm{~cm}$ (magnification = 0.448 ; the object distance was computed from the midpoint of the lens thickness). The upper surface of the lens was approximately $20.3 \mathrm{~cm}$ above the top surface of the stimuli. The lens reduced the apparent length of each side of the square by about $1: 2$.

A three-sided box, $81.3 \mathrm{~cm}$ high $\times 62.9 \mathrm{~cm}$ wide $\times 101.6 \mathrm{~cm}$ long, was made of foam board, to mask the exposure box and to make it impossible for the subjects to determine the height of the stimuli above the table surface (see Figure 1). The room wall formed a fourth side so that only the bottom and the side facing the experimenter were open. The foam board masking box hung over a

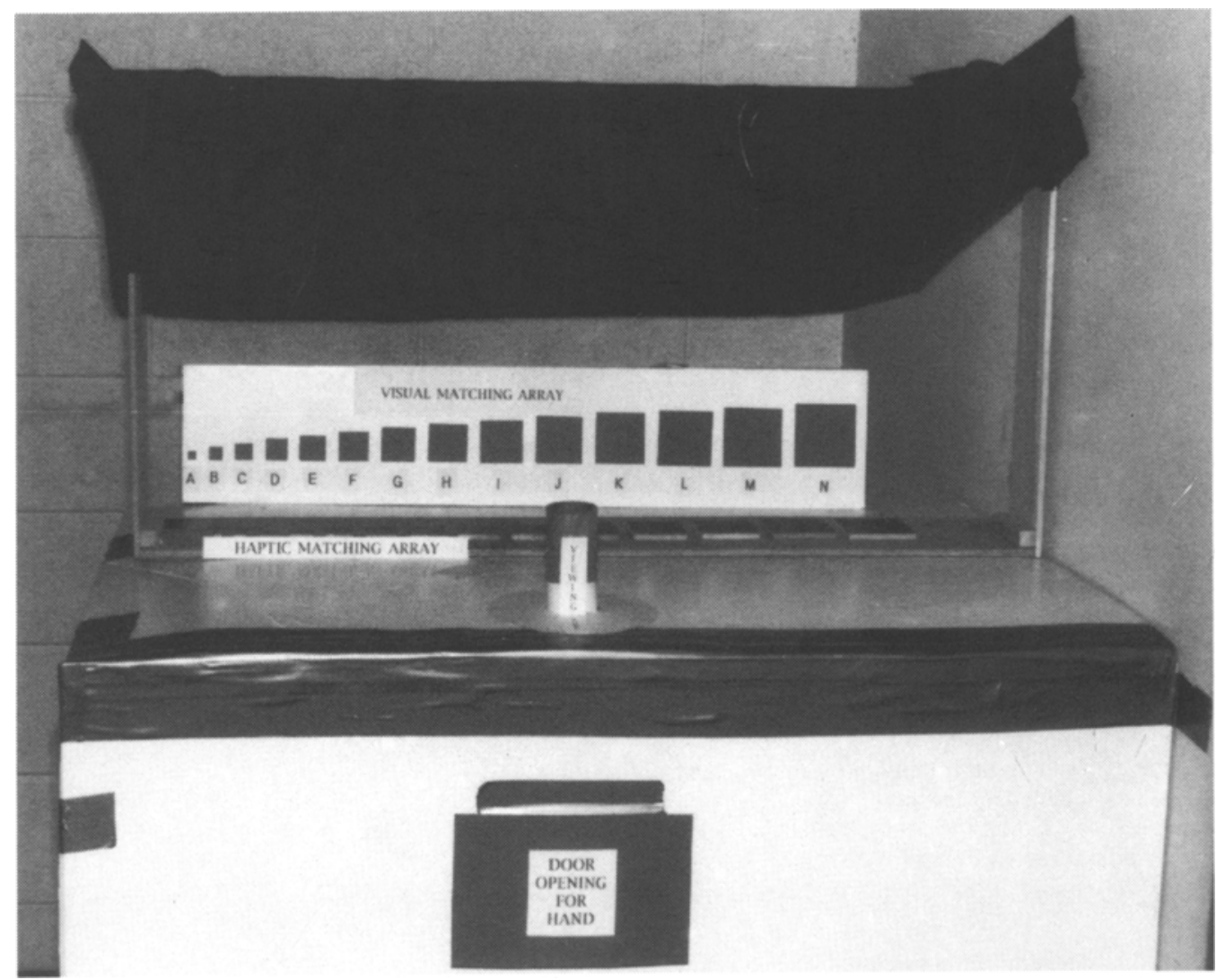

Figure 1. A frontal view of the apparatus used in the experiments, as the subjects enter the experimental room. The curtain and haptic matching array were removed from the top surface of the box for visual judgments. The curtain was down during haptic matching, to prevent vision of the matching stimuli. The viewing tube can be seen on the top of the three-sided box, and the door flap in front allowed subjects access to the stimuli in the examination box when they reached inside. The conflict stimuli were placed in the bottom of the examination box at the level of the bottom of the door flap. The wooden exposure box was masked behind the door flap and placed behind the flap and butted against the top-front edge of the masking three-sided box. The top of the wooden exposure box was just beneath the viewing tube. The exposure box was placed so that the view through the viewing tube was of the center of the bottom of the wooden exposure box. Subjects reached in the box, with the palm down and felt the squares in the examination box while looking at them through the viewing tube at the top-front of the apparatus (in the middle). The door flap prevented subjects from obtaining a normal view of their hands as they touched the stimuli in the examination box, but they could see the squares and the tops of their fingers by looking down through the viewing tube on the top front of the three-sided box. 
table, $70 \mathrm{~cm}$ high, and was supported by a hidden wooden frame. $\mathrm{A}$ stop, a $2.5-\mathrm{cm}$-diameter circular viewing hole, was made on top, with the center $12.7 \mathrm{~cm}$ from the side facing the subject. A $10-\mathrm{cm}-$ long viewing tube $(4.2-\mathrm{cm}$ inner diameter) was attached to the top panel of the box above the stop and the lens, through which the subjects viewed the squares.

A visual response array, $81.6 \mathrm{~cm}$ wide $\times 16 \mathrm{~cm}$ high, was created, using blue posterboard squares with sides ranging from 1 to $7.5 \mathrm{~cm}$, increasing in $0.5-\mathrm{cm}$ increments (see Figure 1). The capital letters A-N, $1.4 \mathrm{~cm}$ high, were placed $1.5 \mathrm{~cm}$ below each square. The array was centered at the midpoint of the lens and viewing tube in the frontal plane, with a $1.5-\mathrm{cm}$ space between the squares.

A haptic matching response array was made of $6.5-\mathrm{mm}$-thick wooden squares mounted on a $96-\mathrm{cm}$-long board, with sides ranging from 1 to $7.5 \mathrm{~cm}$, increasing in $0.5-\mathrm{cm}$ increments. An opaque black cloth was suspended in front of the haptic matching array to block vision. The array was aligned with the center of the lens but was flat on the top surface of the apparatus in the horizontal plane (see Figure 1).

Design and Procedure. The experiment was a between-within design. Independent groups of subjects made haptic matches to haptically presented standards $\left({ }^{*} \mathrm{H}-\mathrm{H}\right)$, visual matches to visually presented standards $\left(\mathrm{v}^{*}-\mathrm{V}\right.$, magnification of standard $\left.=0.448\right)$, or haptic or visual matches to a conflict standard ( $\mathrm{vH}-\mathrm{H}$ or $\mathrm{vH}-\mathrm{V})$. Repeated measures were taken on size of the standard $(4,5$, or $6 \mathrm{~cm})$ and trial blocks ( 10 blocks), with each standard-sized square appearing once in each block in a random order. A single random order was used, with all the subjects starting with the 4-cm square in Experiments 1-3.

Conflict subjects were told to reach inside the door on the front of the apparatus, with their palms facing down, feel the square on the floor of the box, look at it through the viewing tube, and select the matching stimulus that was "the same size as the square really is." There were no restrictions on how the subjects felt the squares beneath their right hands. The subjects could see the squares, the upper surfaces of their fingers, and their hands as they felt the squares. The subjects were told to keep their eyes within less than approximately $8 \mathrm{~cm}$ from the top of the viewing tube, to avoid the possibility of the formation of double images in binocular viewing. Although binocular or monocular viewing was allowed, most subjects opted for monocular viewing with their preferred eye. No headrest was used. Visual matching conflict subjects ( $\mathrm{vH}-\mathrm{V})$ were allowed to visually and haptically examine the standard for as long as they wished and could repeatedly look back and forth from the standard to the visual matching array when making a match. The subjects selected their matches in visual conditions by naming the letter corresponding to the square they chose.

The subjects in the conflict group making haptic matches $(\mathrm{vH}-\mathrm{H})$ were allowed to feel the standards with their right hands while looking at them at the same time and simultaneously to feel the tangible matching array with their left hands. The subjects responded by tapping the squares corresponding to their choices with their left hands. An additional experiment was performed to determine whether the use of the right hand for touching standard stimuli could have produced different data than would have been produced had the left hand been used for examination of the standards. Ten subjects ( 5 males, 5 females) made haptic matches to haptic standards. In this experiment, the variable of hand used for standards and matches was examined, with repeated measures on the subjects (hand was a within-subjects variable). Half of the subjects started by examining the standards with their right hands and feeling the comparison array with their left hands for 15 trials; they then finished with their hands reversed. The other half of the subjects used the opposite sequence. The three standard sizes $(4,5$, and $6 \mathrm{~cm})$ were presented five times each in a random arrangement for one hand and then for another 15 trials for the other hand. The effect of hand $(M$ right $=$ $4.89 \mathrm{~cm} ; M$ left $=4.91 \mathrm{~cm}$ ) was nonsignificant, as was the interaction between hand and size (both $F_{\mathrm{S}}<1$ ). The effect of stimulus size was highly significant $[F(2,18)=334.2, p<.001]$. Thus, one cannot fault the procedure that was used here on the grounds that the subjects always used their right hands for the standard stimuli.

For all the conditions involving sight of the standards, the subjects were not allowed to see the stimuli as they were inserted into or removed from the examination bux. A mat board cover was placed over the stimuli while the squares were inserted into or removed from the box. This ensured that the subjects would not become aware of the distortion induced by the reducing lens. Magnification was progressively altered as the stimulus square was moved into and out of the field of the lens. Examination time was unlimited, and feedback was not given.

\section{Results and Discussion}

Table 1 and Figure 2 show mean size judgments for the standard sizes for the conflict and control groups. Two analyses of variance (ANOVAs) were conducted on the matching size data, comparing the ${ }^{*} \mathrm{H}-\mathrm{H}$ condition with the conflict group making haptic matches $(\mathrm{vH}-\mathrm{H})$ and separately comparing the $\mathrm{v}^{*}-\mathrm{V}$ group with the conflict group making visual matches $(\mathrm{vH}-\mathrm{V})$.

The ANOVA comparing ${ }^{*} \mathrm{H}-\mathrm{H}$ and $\mathrm{vH}-\mathrm{H}$ groups yielded a significant effect of group $[F(1,18)=24.3, p<$ $.0001]$ and a highly significant effect of stimulus size $[F(2,36)=423.3, p<.001]$. The effect of trial block was nonsignificant $(F<1)$. All of the interactions were nonsignificant (all $p \mathrm{~s}>.30$ ).

The second ANOVA compared the $\mathrm{vH}-\mathrm{V}$ and the $\mathrm{v}^{*}-\mathrm{V}$ groups and also yielded a significant effect of group

Table 1

Mean Judged Sizes (in Centimeters) and Standard Deviations as a Function of Group and Size (in Centimeters) of the Stimulus Standards for Experiments 1 and 1A

\begin{tabular}{|c|c|c|c|c|c|c|c|c|c|c|c|c|}
\hline \multirow{4}{*}{$\begin{array}{c}\text { Standard } \\
\text { Size }\end{array}$} & \multicolumn{12}{|c|}{ Stimulus Standard and Matching Modality } \\
\hline & \multicolumn{8}{|c|}{ Experiment 1} & \multicolumn{4}{|c|}{ Experiment $1 \mathrm{~A}$} \\
\hline & \multicolumn{2}{|c|}{$* \mathrm{H}-\mathrm{H}$} & \multicolumn{2}{|c|}{$v^{*}-\mathrm{V}$} & \multicolumn{2}{|c|}{$\mathrm{vH}-\mathrm{H}$} & \multicolumn{2}{|c|}{$\mathrm{vH}-\mathrm{V}$} & \multicolumn{2}{|c|}{$\mathrm{v}^{*}-\mathrm{H}$} & \multicolumn{2}{|c|}{${ }^{*} \mathrm{H}-\mathrm{V}$} \\
\hline & $M$ & $S D$ & $M$ & $S D$ & $M$ & $S D$ & $M$ & $S D$ & $M$ & $S D$ & $M$ & $S D$ \\
\hline 4 & 3.92 & 0.27 & 1.71 & 0.30 & 2.90 & 0.52 & 2.64 & 0.37 & 1.47 & 0.25 & 4.07 & 0.51 \\
\hline 5 & 4.87 & 0.36 & 2.28 & 0.33 & 3.93 & 0.51 & 3.84 & 0.49 & 1.93 & 0.29 & 5.30 & 0.56 \\
\hline 6 & 5.68 & 0.42 & 2.81 & 0.44 & 4.74 & 0.64 & 4.97 & 0.81 & 2.52 & 0.48 & 6.15 & 0.55 \\
\hline
\end{tabular}

Note-Magnification $=0.448 ; n=10$ per group. 


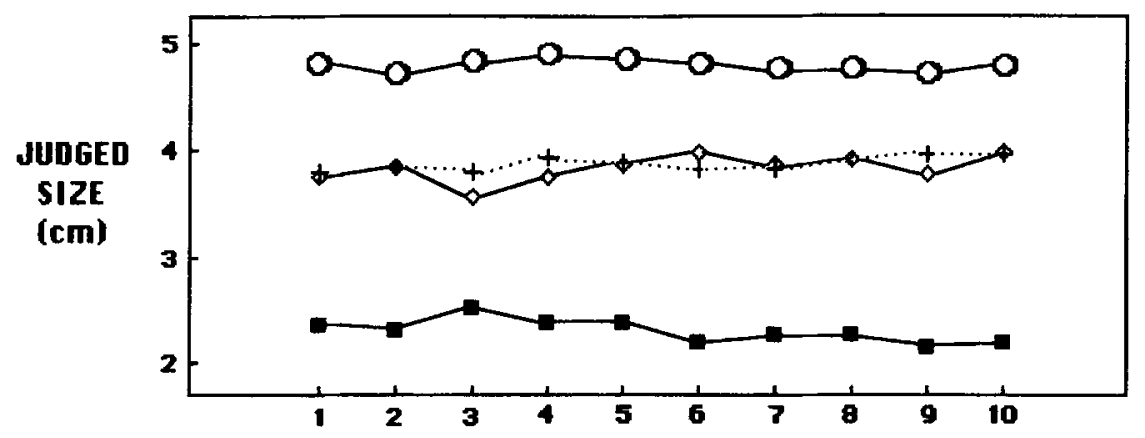

THIAL BLOCK

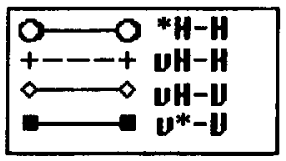

Figure 2. Mean size judgments over trial block in Experiment 1. Conflict subjects made their matching judgments, using touch (vH-H) or vision (vH-V). Control, intramodal subjects made visual matches to minified standards $\left(v^{*}-V\right)$ or haptic matches to stimuli they touched $\left({ }^{*} \mathbf{H}-\mathbf{H}\right)$.

$[F(1,18)=62.5, p<.0001]$ and stimulus size $[F(2,36)=$ $196.1, p<.001]$. The main effect of trial block was nonsignificant $(F<1$; see Figure 2$)$. The interaction between group and trial block failed to reach significance $[F(9,162)$ $=1.6, p=.13]$. However, the interaction between group and stimulus size was highly significant $[F(2,36)=25.4$, $p<.001]$. Touch became more salient in the conflict group at the larger sizes (see Table 1). The simple effect of group was significant for all three stimulus sizes (all $p s<$ $.001)$. Again, conflict subjects' judgments were about midway between the control conditions (see Figure 2).

The conflict subjects adopted judgments midway between perceived haptic size $(M=4.83 \mathrm{~cm})$ and perceived visual size with minification $(M=2.27 \mathrm{~cm})$, with little evidence of dominance by one modality. The judgments for the $\mathrm{vH}-\mathrm{V}$ subjects $(M=3.80 \mathrm{~cm})$ were almost identical to those for the $\mathrm{vH}-\mathrm{H}$ subjects $(M=3.85 \mathrm{~cm})$. Judgments in the conflict conditions were actually slightly closer to the ${ }^{*} \mathrm{H}-\mathrm{H}$ mean than a simple compromise between the ${ }^{*} \mathrm{H}-\mathrm{H}$ and $\mathrm{v}^{*}-\mathrm{V}$ means would predict (arithmetic $M=3.55 \mathrm{~cm}$ ).

Separate ANOVAs were performed on the data for the first block of trials. The conflict group making visual judgments was compared with the visual, intramodal controls, and this yielded a significant effect of group $[F(1,18)=$ $30.98, p<.001]$, a significant effect of size $[F(2,36)=$ $45.3, p<.001]$, and a significant interaction $[F(2,36)=4.5$, $p=.018$ ]. However, the simple effects of group were significant for all levels of size (all $p s<.01$ ). The interaction reflected increased differences between the groups as the stimuli became larger. A separate ANOVA was conducted on the first block of trials, comparing the conflict group making haptic matches with the haptic, intramodal control group. Again, the effect of group was highly significant $[F(1,18)=17.84, p<.001]$, and the effect of size was significant $[F(2,36)=119.57, p<.001]$, but the interaction was nonsignificant $(F<1)$. On the very first trial, the results were similar to those of the overall analyses.

It should be noted that the obtained results were not fully consistent with the effects of matching modality reported by Hershberger and Misceo (1996). They reported that visual matching conditions yielded discrepancy judgments that were much closer to those for vision and that haptic matching in conflict conditions yielded judgments that were closer to those of haptic, intramodal controls. They interpreted these findings as an indication of haptic dominance with haptic matching. Furthermore, the subjects in the first experiment reported here showed no main effect of trial block and no significant interaction between group and trial block. This means that the visual adaptation explanation can be rejected. Also, the lack of a trial block effect in Experiment 1 argues against the idea that touch increases in potency over blocks of trials. Perhaps these differences between the present results and those reported by Hershberger and Misceo's study are the result of their subjects' receiving control trials prior to conflict trials. It is also possible, however, that sight of the bare hand matters. Subjects may be less likely to show a simple reliance on vision when they are able to see their hands as they feel stimuli, a natural state of affairs (see, also, Heller, 1992). It is also likely that the different outcome is the result of differential memory demands for vision and for touch, as well as modalityspecific retention differences between these modalities. It should be noted that the conflict subjects in Experiment 1 yielded size judgments that were close to Hershberger and Misceo's estimate of the grand mean for their 
control subjects' performance on the first trial, perhaps indicating little response bias. Note that the mean for the $\mathrm{V}^{*} \mathrm{~V}$ group $(2.27 \mathrm{~cm})$ was identical to that reported by Hershberger and Misceo $(2.27 \mathrm{~cm})$, despite the use of a different lens.

One reviewer pointed out that the subjects in the visual matching condition could look away from the discrepancy stimuli. The present procedures were adopted to eliminate the memory load for touch, but had the effect of making matching nearly, but not quite, simultaneous for vision. Conceivably, this may have reduced the effect of intersensory conflict in that case, resulting in the appearance of a haptic bias. On this interpretation of the results of Experiment 1, vision may have become less salient when the subjects looked away from the viewing tube to make their matches. It is unlikely that the subjects became more aware of the discrepancy over trial block because of this procedure, since an examination of Figure 2 does not provide much evidence for a trial block effect. Also, it is unconvincing to argue that sequential visual matching induces visual dominance (e.g., Hershberger \& Misceo, 1996) and then to claim that use of a sequential visual matching procedure will induce haptic dominance. The results of Experiment 3 in the present study also argue against this interpretation.

This reviewer also noted that the virtual image sizes do not correspond exactly to choices. Thus, $0.448 \times$ $6 \mathrm{~cm}=2.688 \mathrm{~cm}$, which falls between the choices of 2.5 and $3.0 \mathrm{~cm}$ in control conditions. Recall, however, that mean $\mathrm{v}^{*}-\mathrm{V}$ judgments in the present experiment were comparable with those reported by Hershberger and Misceo (1996).

\section{EXPERIMENT 1A}

One might expect that the matching modality would influence the size of the judgments in any cross-modal condition (matching in a different modality), even when there is no intersensory conflict (see Table 1). Therefore, it may matter whether subjects make haptic or visual matches when feeling or seeing haptic or visual standards, independent of any discrepancy conditions. Consequently, an additional two groups of subjects were asked to make size matches to visually or haptically presented standards, with matching in the other modality for crossmodal matches $\left({ }^{*} \mathrm{H}-\mathrm{V}, 4\right.$ males and 6 females; $\mathrm{v}^{*}-\mathrm{H}$, 5 males and 5 females). These cross-modal groups (12 subjects were right-handed, 8 left-handed) were compared with the intramodal ${ }^{*} \mathrm{H}-\mathrm{H}$ and $\mathrm{v}^{*}-\mathrm{V}$ groups from Experiment 1, which used matching in the same modality. An ANOVA on the mean size data for these four groups showed highly significant effects of group $[F(3,36)=195.94, p<.001]$ and size $[F(2,72)=$ $534.20, p<.001]$, but the main effect of trial block was nonsignificant $(F<1)$. However, the interaction between group and trial block was significant $[F(27,324)=1.79$, $p=.01]$, as was the interaction between size and trial block $[F(18,648)=1.83, p<.02]$. The simple effect of trial block was only significant for the $* \mathrm{H}-\mathrm{V}$ subjects $(p=.001)$.

In an attempt to better understand cross-modal effects, an additional ANOVA compared the $\mathrm{v}^{*}-\mathrm{V}$ group with $\mathrm{v}^{*}-\mathrm{H}$ subjects and found a marginally significant effect of matching modality $[F(1,18)=3.95, p=.062]$, with a highly significant effect of stimulus size $[F(2,36)=$ $215.4, p<.001]$. The main effect of trial block was nonsignificant $(F<1)$, but the interaction between matching modality and trial block was significant $[F(9,162)=2.08$, $p<.05]$, and the interaction between size and trial block was also significant $[F(18,324)=1.65, p<.05]$. The other interactions were nonsignificant (all $F \mathrm{~s}<1$ ). Simple effects of group at each level of trial block were computed, to clarify the interaction effect, and revealed that the effect of group was highly significant for the first five blocks of trials (all $p s<.05$ ) but nonsignificant for the last five blocks of trials (all $p \mathrm{~s}>.05$ ). This implies that the subjects changed their judgments rapidly over trial block and that practice with cross-modal matching tends to overcome earlier, less veridical judgments.

The obtained interactions between cross-modal matching and trial block make it difficult to interpret the results of conflict conditions, since they involve cross-modal matching conditions ( $\mathrm{vH}-\mathrm{V}$ or $\mathrm{vH}-\mathrm{H})$. Judgments can change rapidly over the first few trials, and matching modality can alter size judgments. If it appears that the subjects are making compromise judgments, they may actually be very uncertain about the true size of a stimulus, even without manipulating visual information.

\section{EXPERIMENT 2 \\ The Effect of Sight of the Hand and Prior Information on Perceived Size Under Minification}

The purpose of Experiment 2 was to determine whether sight of the hand and a familiar object, a coin, would alter size judgments. This was studied because some subjects in Experiment 1 expressed awareness of the presence of the lens or of the effect of the lens during conflict trials. All the subjects in Experiment 2 viewed three sizes of squares through a reducing lens and made visual matches. The subjects only used vision in Experiment 2, since it was designed to discover whether visual information about the distorting effect of the lens would alter size estimates. The subjects were expected to increase their size estimates as a function of knowledge of the minifying effect of the reducing lens.

Judgments were repeated over blocks of trials in order to decide between alternative explanations of the data in Hershberger and Misceo (1996). If visual adaptation to the lens occurs over trial blocks, size estimates should grow as a function of trial block, because of the diminished effect of the reducing lens. Also, if the subjects gain awareness of the discrepancy or if touch grows more potent, as a function of experience, one should find increases in size estimates over blocks of trials. 


\section{Method}

Subjects. Forty undergraduates ( 10 in each group; 4 male, 6 female) participated for course credit. There were four groups of subjects: no-information (NI), sight of quarter $(\$ 0.25, \mathrm{SQ})$, sight of quarter and experimenter's fingers (SQEF), and sight of quarter and subject's fingers (SQSF).

Stimuli and Apparatus. The stimuli consisted of three blue posterboard squares, with sizes being the same as those in Experiment 1 . Each square was mounted on a foam board panel, $17.5 \times 19.5 \mathrm{~cm}$. A quarter (\$0.25) was mounted on a piece of $17.5 \mathrm{~cm} \times 19.5 \mathrm{~cm}$ foam board or braille paper for presentation to the subjects. The visual matching array of Experiment 1 was used for size estimates.

Design and Procedure. During the size judgment task, the subjects saw the squares in the box and were asked to estimate their sizes by naming the letter that corresponded to the stimulus of their choice in the visual matching array. Feedback was not given.

The experiment was a between-within design, with the betweengroup factor being prior information (NI, SQ, SQEF, and SQSF), with repeated measures on size and trial blocks. In all cases, there were 10 blocks of trials, with each size of square appearing once in each block in a random order.

For the control NI group, the subjects were told to give the size of the square by making a visual match. They were told nothing else about the procedure. Ten additional subjects were shown the quarter (SQ group) outside and then minified inside the box only and then were asked, "What do you see?" No further information was given. These subjects did not see the quarter as it was inserted into the examination box. Those subjects who asked whether they should report the apparent image size or the true size were told "you decide." An additional group of subjects was given objective instructions. They saw the quarter inside and outside of the box, saw the experimenter's fingers and hand (SQEF group) through the reducing lens before trials began, but were told to give the size it "actually is, not how big it looks." A final group of subjects saw the quarter inside and outside of the box and their own minified hand (SQSF group) in the box. These subjects were allowed to examine the quarter outside of the box and then to visually and tactually examine the quarter in the examination box with their preferred hands. These information manipulation conditions were accomplished prior to size judgments, at the beginning of the experimental session.

\section{Results and Discussion}

Mean size judgments increased as a function of information, with the NI group yielding the smallest judged size $(M=2.27 \mathrm{~cm})$ and the largest judgments being obtained when subjects could see their hands $(M$ SQSF $=$ $4.12 \mathrm{~cm}$; see Table 2 and Figure 3). The effect of infor-

Table 2

Mean Judged Size (in Centimeters) and Standard Deviations as a Function of Prior Information and Size of Stimulus Modality (in Centimeters) for Experiment 2

\begin{tabular}{|c|c|c|c|c|c|c|c|c|}
\hline \multirow{3}{*}{$\begin{array}{l}\text { Stimulus } \\
\text { Modality }\end{array}$} & \multicolumn{8}{|c|}{ Prior Information Group } \\
\hline & \multicolumn{2}{|c|}{ NI } & \multicolumn{2}{|c|}{ SQ } & \multicolumn{2}{|c|}{ SQEF } & \multicolumn{2}{|c|}{ SQSF } \\
\hline & $M$ & $S D$ & $M$ & $S D$ & $M$ & $S D$ & $M$ & $S D$ \\
\hline 4 & 1.75 & 0.20 & 2.13 & 0.62 & 2.85 & 1.00 & 3.08 & 0.70 \\
\hline 5 & 2.26 & 0.25 & 2.90 & 0.91 & $3.8 \mathrm{I}$ & 1.22 & 4.19 & 1.09 \\
\hline 6 & 2.81 & 0.47 & 3.78 & 1.32 & 4.85 & 1.54 & 5.10 & 1.35 \\
\hline
\end{tabular}

Note-NI, no information; SQ, sight of quarter; SQEF, sight of quarter and experimenter's fingers; SQSF, sight of quarter and subject's fingers. Magnification $=0.448, n=10$. mation on judged size was highly significant $[F(3,36)=$ $8.25, p<.001]$, and a Newman-Keuls test found that the means all differed significantly (all $p \mathrm{~s}<.05$ ), with two important exceptions (NI vs. SQ, $p>.05$; SQSF vs. SQEF, $p>.05$ ). The effect of stimulus size was highly significant $[F(2,72)=192.52, p<.001]$. The effect of trial block was also significant $[F(9,324)=5.07, p<.001]$.

The data also revealed significant interactions between information condition and size $[F(6,72)=3.55$, $p<.01]$ and between trial block and size $[F(18,628)=$ $2.38, p=.001]$. The simple effect of information type was significant for all three stimulus sizes (all $p s<.02$ ). The effect of prior information became more striking for larger stimuli (see Table 2). The interaction between information and trial block was nonsignificant $[F(27,324)=$ $1.37, p>.10]$, as was the triple interaction between information, size, and trial block $(F=1.07)$. There was little change over trial block for the NI group (see Figure 3 ).

The highly significant effect of information condition consisted of subjects' increasing their mean size judgments when they saw a hand in the viewing chamber. It did not matter whether the hand was that of the subject or belonged to the experimenter. This means that information about the nature of the manipulation of vision can serve to increase size judgments in visual conditions, and this occurs in the first trial block with sight of a bare hand. Thus, increases in perceived size over blocks of trials in conflict conditions in Hershberger and Misceo (1996) may not represent the expanded influence of haptics on perceived size, as one might assume. Subjects may alter their judgments within vision, when given information about the artificial manipulation of vision. Conceivably, there is no immediate awareness of the size and scale of the hand in early trials when viewing the stimulus and feeling from below, through a cloth, as in Hershberger and Misceo. When one feels a square through a cloth, one can "see the fingertips" move, as one sees the cloth move. However, it is probable that subjects can make use of this information over a series of blocks of trials. That means that if subjects continue to see themselves feeling a shape from underneath and through a cloth, they may eventually know (consciously or unconsciously) that their fingers are minified. The lack of a trial block $X$ information interaction in Experiment 2 is consistent with this analysis. The data from Experiment 2 also show that subjects will provide mean visual size estimates of over $4 \mathrm{~cm}$ (for the 5-cm stimulus) in both the SQEF and the SQSF groups. This judged size is like that reported by Hershberger and Misceo in haptic matching to conflict stimuli (about $4 \mathrm{~cm}$ on the first block of trials).

In a similar vein, one reviewer pointed out that the subjects in the present experiment and in the conflict experiments reported here experienced an intrasensory conflict. The visual angle of the seen stimulus is small, but information about true size is provided by seeing the stimulus next to the subject's own hand. This provides 

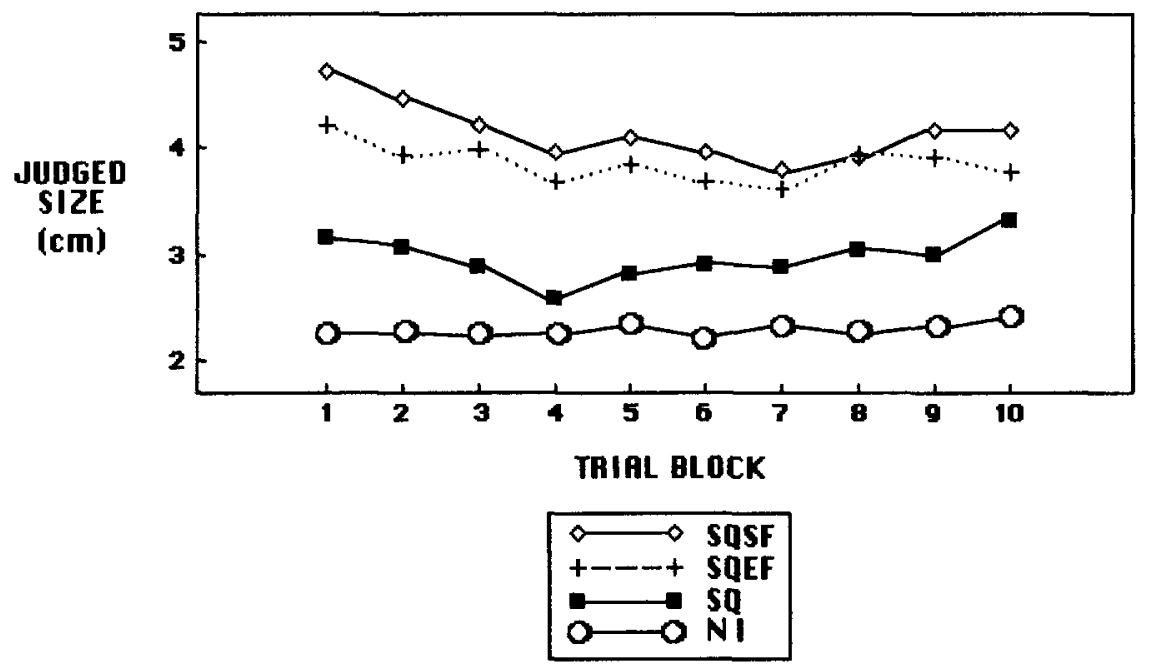

\begin{abstract}
Figure 3. Mean size judgments over trial block as a function of information condition in Experiment 2. The subjects had no prior information in the no-information group (NI). The subjects in the quarter group (SQ $=$ sight of quarter) saw a quarter $(\mathbf{\$ 0 . 2 5})$ in the viewing chamber. The subjects in the experimenter's fingers group (SQEF = sight of quarter and experimenter's fingers) saw the experimenter touch the quarter $(\$ 0.25)$ in the viewing box, whereas the subjects in the subject's fingers group (SQSF = sight of quarter and subject's fingers) saw their own hands in the viewing box as they touched a quarter.
\end{abstract}

some indication of how large it really is. This could have contributed to the apparent lack of dominance in conflict conditions in Experiment 1.

Thus, Hershberger and Misceo's (1996) results indicating haptic dominance may not mean that haptics had any influence on perceived size. Subjects may have shown the influence of vision of the hand. Without the additional frame-of-reference information given by an object of known size and known distance (the hand and quarter), subjects have no way of knowing how large the squares are through vision. However, after they have seen their hands and the quarter, they increase size estimates.

Note that judged size did not increase but seemed actually to decrease over trials (see Figure 3 ). It is not clear why this occurred, but it may reflect an increase in the power of vision over trial block in the absence of touch.

\section{EXPERIMENT 3 Absolute Visual Size Judgments}

The purpose of Experiment 3 was to present an intersensory conflict but to require absolute size judgments. In most other respects, the design and procedure were like those of Experiment 1 for the subjects who made visual matches. Absolute size judgments were required because it was possible that the subjects made ostensibly veridical size matches in intramodal control conditions in Experiment 1 , yet did not really possess a precise size metric. The basic problem is that differences of $0.5 \mathrm{~cm}$ are rather coarse; yet, that was the size difference between the matching squares in Experiments 1 and 2.
In Experiment 3, the subjects made absolute size judgments by looking at a metric ruler, placed on top of the apparatus. There were three groups of subjects in Experiment 3. Two groups made visual absolute size estimates of visually $\left(\mathrm{v}^{*}-\mathrm{V}\right)$ or haptically $\left({ }^{*} \mathrm{H}-\mathrm{V}\right)$ presented standard stimuli. A conflict (vH-V) group of subjects felt the squares while viewing them but also made absolute size estimates through sight of the ruler.

\section{Method}

Subjects. There were 10 subjects in each of the three groups, with subjects making absolute visual judgments in the conflict group (vH-V; 6 females and 4 males; 9 right-handed, 1 lefthanded), the visual standard group ( $\mathrm{v}^{*}-\mathrm{V} ; 6$ females and 4 males; 9 right-handed, 1 left-handed), and the haptic standard group ( ${ }^{*} \mathrm{H}-\mathrm{V} ; 6$ females and 4 males; 9 right-handed, 1 ambidextrous).

Stimuli and Apparatus. In most respects, the apparatus was identical to that of Experiments 1 and 2. A double-concave lens with a focal length of $200 \mathrm{~mm}$ was used in place of the plano-concave

Table 3

Mean Judged Size (in Centimeters) and Standard Deviations as a Function of Group and Size (in Centimeters) of the Stimulus Standards in Experiment 3

\begin{tabular}{|c|c|c|c|c|c|c|}
\hline \multirow{3}{*}{$\begin{array}{c}\text { Stimulus } \\
\text { Size }\end{array}$} & \multicolumn{6}{|c|}{ Stimulus Standard and Matching Modality } \\
\hline & \multicolumn{2}{|c|}{${ }^{*} \mathrm{H}-\mathrm{V}$} & \multicolumn{2}{|c|}{$v^{*}-V$} & \multicolumn{2}{|c|}{$\mathrm{vH}-\mathrm{V}$} \\
\hline & $M$ & $S D$ & $M$ & $S D$ & $M$ & $S D$ \\
\hline 4 & 3.28 & 0.81 & 1.81 & 0.43 & 2.33 & 0.30 \\
\hline 5 & 4.57 & 1.33 & 2.34 & 0.44 & 3.15 & 0.39 \\
\hline 6 & 5.85 & 1.76 & 3.13 & 0.59 & 3.97 & 0.52 \\
\hline
\end{tabular}

Note Absolute metric judgments; magnification $=0.5 . n=10$ per group. 

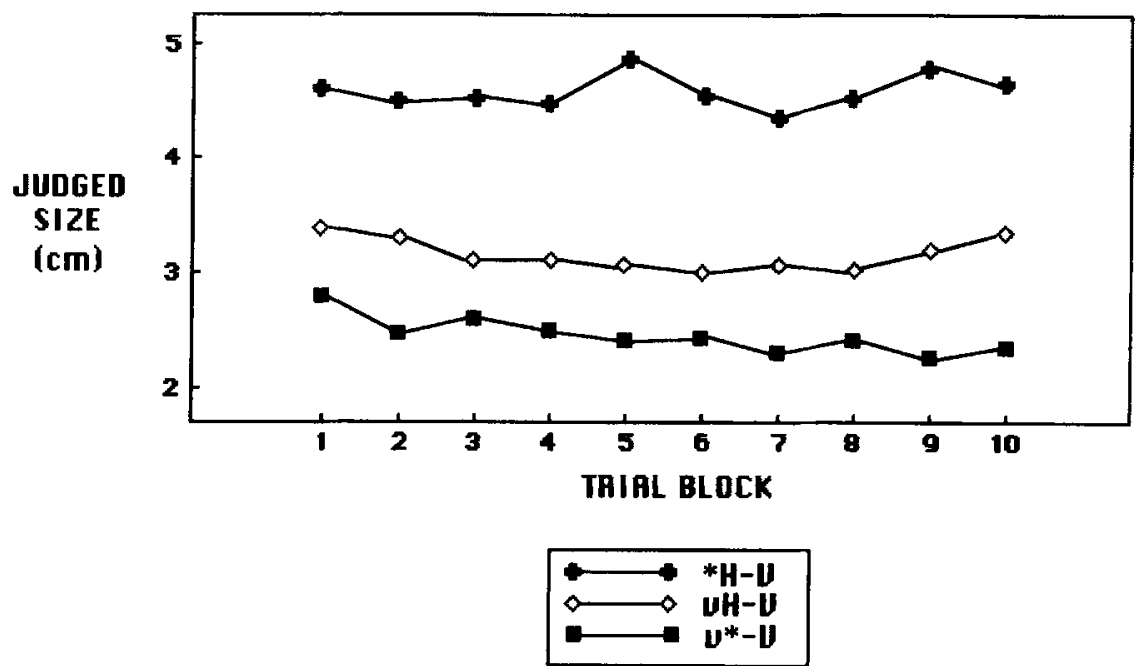

Figure 4. The results of Experiment 3, with all the subjects making absolute visual size estimates, using sight of a metric ruler for their judgments. Data over trial block can be seen for conflict subjects $(\mathrm{vH}-\mathrm{V})$, visual controls $\left(\mathrm{v}^{*}-\mathrm{V}\right)$, and haptic controls $\left({ }^{*} \mathrm{H}-\mathrm{V}\right)$.

lens of Experiments 1 and 2. This yielded image magnification of approximately 0.5 . A different lens was used in the first two experiments as an expedient, since it was readily available. Subsequently, we obtained a lens that allowed us to more precisely produce the desired 0.5 magnification. Note that the change in the lens could not explain the results of Experiments 3 and 4, since the change in magnification was very small. In addition, in Experiment 1 , it was found that the mean for the $\mathrm{v}^{*}-\mathrm{V}$ group $(2.27 \mathrm{~cm})$ was identical to that reported by Hershberger and Misceo $(1996,2.27 \mathrm{~cm})$, despite the use of a different lens. Also, an explicit comparison between the lenses used in the present experiment yielded very small differences in apparent size. These data are reported later in this article. A metric ruler $(30.5 \times 2.54 \mathrm{~cm})$ was placed with its long axis horizontal and perpendicular to the subjects' line of sight. Its midpoint was placed at a distance of $41.5 \mathrm{~cm}$ from the viewing tube, and the flat of the ruler was in the frontal plane.

Design and Procedure. The experiment took the form of a between-within design. One group experienced a conflict $(\mathrm{vH}-\mathrm{V})$, whereas the modality of the standards was varied in the two groups without conflict $\left({ }^{*} \mathrm{H}-\mathrm{V}\right.$ and $\left.\mathrm{v}^{*}-\mathrm{V}\right)$; the within-group variables included size of the standards $(4,5$, and $6 \mathrm{~cm})$ and trial block $(10)$.

Conflict subjects were told to examine the square in the box and to decide "how large it really is." They were told to indicate their size judgments with the aid of a reference ruler in clear sight. The subjects were told to look at the square through the viewing tube while feeling it and to give their measurements in metric measure, by looking at the available ruler. In other respects, the procedure was similar to that of Experiment 1 . In addition, the subjects were not allowed to place their hands anywhere near the ruler. They were told that they could give their judgments in whole centimeters or in centimeters and millimeters (i.e., $10.7 \mathrm{~cm}$ or $10.8 \mathrm{~cm}$ was allowed, but not $10.75 \mathrm{~cm}$ ).

\section{Results and Discussion}

Table 3 shows a summary of the results of Experiment 3, with the data collapsed over trial block. Figure 4 shows matching judgments as a function of trial block. The subjects tended to rely on vision in the conflict group $(M=$ $3.15 \mathrm{~cm}$ ), since their judgments were much closer to the
$\mathrm{V}^{*} \sim \mathrm{V}$ mean $(M=2.43 \mathrm{~cm})$ than were those obtained for the ${ }^{*} \mathrm{H}-\mathrm{V}$ subjects $(M=4.57 \mathrm{~cm})$. A between-within ANOVA showed a highly significant effect of group $[F(2,27)=17.94, p<.001]$, and the effect of size was significant $[F(2,54)=187.72, p<.001]$. The main effect of trial block was nonsignificant $[F(9,243)=1.77, p=.075]$.

The data also revealed a significant interaction between group and size $[F(4,54)=7.88, p<.001]$. Tests of simple effects revealed significant effects of group at all sizes (all $p s<.01$ ). The interaction derived from a smaller effect of stimulus size for the $v^{*}-V$ group.

There was also a significant interaction between size and trial block $[F(18,486)=2.12, p<.01]$. The simple effect of trial block was significant for the $4-\mathrm{cm}$ stimuli $[F(9,243)=3.27, p=.001]$, but not for the 5 -cm stimuli $(F<1)$, and was marginally significant for the largest, 6 -cm stimuli $[F(9,243)=1.88, p=.055]$. The size $X$ trial block interaction derived from subjects' making similar judgments for the 4 - and the 5-cm standards, but only on the first trial block (see Tables 3 and 4). The data seem generally consistent with those of Hershberger and Misceo (1996).

Table 4

Mean Judged Size (in Centimeters) and Standard Deviations as a Function of Group and Size (in Centimeters) of the Stimulus Standards for the First Block of Trials in Experiment 3

\begin{tabular}{|c|c|c|c|c|c|c|}
\hline \multirow{3}{*}{$\begin{array}{c}\text { Stimulus } \\
\text { Size }\end{array}$} & \multicolumn{6}{|c|}{ Stimulus Standard and Matching Modality } \\
\hline & \multicolumn{2}{|c|}{${ }^{*} \mathrm{H}-\mathrm{V}$} & \multicolumn{2}{|c|}{$\mathrm{v}^{*}-\mathrm{V}$} & \multicolumn{2}{|c|}{$\mathrm{vH}-\mathrm{V}$} \\
\hline & $M$ & $S D$ & $M$ & $S D$ & $M$ & $S D$ \\
\hline 4 & 3.65 & 0.78 & 2.40 & 0.57 & 2.70 & 0.48 \\
\hline 5 & 4.40 & 0.97 & 2.44 & 0.44 & 3.20 & 0.71 \\
\hline 6 & 5.80 & 1.63 & 3.45 & 0.96 & 4.21 & 0.84 \\
\hline
\end{tabular}

Note-Absolute metric judgments; magnification $=0.50 . n=10 \mathrm{per}$ group. 
A separate ANOVA was performed on the data for the first block of trials (see Table 4). The effect of group was significant $[F(2,27)=18.59, p<.01]$, as was the effect of size $[F(2,54)=42.57, p<.01]$, but the interaction between size and group was nonsignificant $[F(4,54)=$ $1.75, p=.154]$. Mean judgments indicate that, although there may be some compromise between the senses, even on the first trial block, the $\mathrm{vH}-\mathrm{V}$ judgments tended to be much closer to those for $\mathrm{v}^{*}-\mathrm{V}$.

Note that the results of Experiment 3 were somewhat different from those of Experiment 1. The subjects in Experiment 1 showed no dominance, regardless of the matching modality. Thus, their judgments were nearly identical for the $\mathrm{vH}-\mathrm{V}$ and the $\mathrm{vH}-\mathrm{H}$ groups (see Figure 2). However, the subjects in the present experiment seemed to show a clearer reliance on vision on the first trial when confronted with a size discrepancy. It is unlikely that the differences between the data from Experiments 1 and 3 could be explained solely in terms of differences in magnification, since these differences were rather small in these experiments ( 0.448 vs. 0.5 ; but see Heller, 1985; Power, 1980, 1981). Heller (1985) reported that weak positive magnification had no effect on perceived texture. However, stronger magnification increased perceived roughness, but only for the smoothest textures, in a cross-modal, haptic-visual matching procedure.

It was necessary to exclude the possibility that the different data from Experiments 1 and 3 derived from the use of different magnification. Consequently, an additional group of subjects ( $n=10,6$ females and 4 males) attempted haptic matches to discrepancy stimuli, but with the same reducing lens that was used in Experiment 3 ( 0.5 magnification). An ANOVA on these data and those of Experiment $3(\mathrm{vH}-\mathrm{H})$ yielded a nonsignificant effect of magnification $[F(1,18)=2.87, p>.10]$. This means that the difference between the results of Experiments 1 and 3 cannot be explained solely in terms of the powers of the reduction lenses that were used. The data support the conclusion that the response measure was important, with absolute judgments with the use of the ruler being more likely to yield visual dominance.

The matching paradigm may not fully reveal the nature of the processes involved when subjects experience an intersensory conflict, and it may be erroneous to assume that they routinely make compromise judgments and average the impressions derived from the conflicting senses. This analysis is entirely consistent with subjects' reports on the difficulty they had making size estimates in conflict conditions. The matching procedure may impose an additional attentional load that diverts subjects' attention from tactual input from the other hand, in the conflict situation. One subject, for example, said that she was not able to tell how large the squares were with the sense of touch, and so she looked at how her fingers covered the discrepancy stimulus. She said that she then looked at the matching array and tried to imagine how her fingers would look if juxtaposed over the array. Thus, some subjects may have used vision for discrepancy judgments, even when the judgments seemed as large as those in the haptic $\left({ }^{*} \mathrm{H}-\mathrm{H}\right)$ conditions.

When asked, after the conclusion of the experiment, 2 of the subjects reported awareness that their hands looked smaller in early trials in the $\mathrm{vH}-\mathrm{V}$ group. One of the subjects reported that he became aware of the lens "after the second or third trial." Three of the subjects said that they used the known width and length of their fingers to "measure" the sizes of the stimuli. Two subjects in the $\mathrm{v}^{*}-\mathrm{V}$ group thought that the distance of the standards changed over trials.

Three of the $\mathrm{vH}-\mathrm{H}$ subjects in Experiment 1 used the fingers as a measuring guide for size judgments, and 2 of the subjects in the $\mathrm{vH} \mathrm{V}$ group reported a similar strategy. Note that Power (1980) prevented his subjects from using measuring strategies, and this could have promoted visual dominance by artificially restricting tactual exploration. Hershberger and Misceo (1996) instructed their subjects to grasp the squares, but they did not indicate whether they prevented subjects from attempting measuring strategies.

Perhaps the viewing arrangement induced some apparent size reduction in visual conditions, even without a reducing lens. Viewing conditions were not normal, since subjects examined the stimuli through a viewing tube with an aperture above the lens. An additional comparison group of subjects made visual size estimates without a reducing lens in the display. A clear, glass ultraviolet photographic filter (UV, $49 \mathrm{~mm}$ in diameter) was placed in the path of the viewing tube. The filter reduces the effects of ultraviolet light on photographic film but does not appreciably alter the visible spectrum.

An analysis of variance compared this no-magnification, visual, intramodal group with the 0.5 -magnification reducing lens group ( $\mathrm{v}^{*}-\mathrm{V}$ ) of Experiment 3 . The effect of magnification (the reducing lens) was significant $[F(1,18)=39.72, p<.01]$. Mean judged sizes, in size order, for the intramodal vision, no-magnification condition were $3.07,3.89$, and $5.21 \mathrm{~cm}$. Thus, judgments were somewhat smaller than those for ${ }^{*} \mathrm{H}-\mathrm{V}$ in Experiment $3[F(1,18)=1.22, p=.28]$. This means that the use of a viewing tube and stop induced some reduction in perceived stimulus size, even without a reducing lens. Although viewing conditions in the present experiments were not identical to those of Hershberger and Misceo (1996), they also used a viewing tube (tapered from 7.5 to $5.1 \mathrm{~cm}$ ) to hold their negative meniscus lens. These data from the different viewing conditions suggest that one cannot assume that a negative lens will produce perceptual effects corresponding to exactly 0.5 image magnification, even if it is placed at a physical distance from an object that is the same as the focal length marked by the manufacturer.

\section{EXPERIMENT 4 Pincers Haptic Size Estimates}

Prior research demonstrated the importance of the matching modality for the resolution of an intersensory 
conflict. Experiment 1 yielded no dominance by either modality, but Experiment 3 yielded judgments that were apparently closer to that of the $\mathrm{V}^{*}-\mathrm{V}$ subjects. These data from Experiment 3 were consistent with those of Hershberger and Misceo (1996), who argued that dominance may reflect the modality used to judge comparison stimuli. Furthermore, subject reports in Experiment 1 also suggested that the matching paradigm could induce attentional difficulties for touch. The first author (M.A.H.) also experienced attentional difficulties while examining stimuli in the conflict condition (see, also, Bartley, 1953). He noticed that he could not really tell how large the stimuli felt while looking at them through the reducing lens and feeling them with a grasping motion of the fingers or of the index finger and thumb. The effect of visual stimulation was to make it impossible to judge how wide apart his fingers were being held while he was simultaneously feeling the matching squares.

Consequently, Experiment 4 adopted a useful and ecologically valid method for making size estimates. The subjects judged size in haptic, intramodal conditions and in conflict conditions by holding their hands behind a curtain and making a pincers posture of their index fingers and thumbs. This technique has been used for the study of the horizontal-vertical illusion in touch (Heller \& Joyner, 1993) and of intersensory conflict in a motor memory task involving the grasping of cylinders (see Gentilucci, Daprati, Toni, Chieffi, \& Saetti, 1995).

\section{Method}

Subjects. There were 10 subjects in each of the three groups$\mathrm{vH}-\mathrm{H},{ }^{*} \mathrm{H}-\mathrm{H}$, and $\mathrm{v}^{*}-\mathrm{H}(\mathrm{N}=30)$. As was indicated by writing preference, all of the *H-H subjects ( 5 males, 5 females) were righthanded, with the exception of one male, who was self-identified as ambidextrous. The conflict group $(\mathrm{vH}-\mathrm{H})$ had 5 males and 5 females; 8 of the subjects were right-handed, 1 male was left-handed, and another male was self-identified as ambidextrous. The $v^{*}-\mathrm{H}$ group had 4 males and 6 females; 9 subjects were right-handed, and 1 was left-handed.

Stimuli and Apparatus. The stimuli and apparatus were like those in Experiment 3, with a magnification of approximately 0.5 $x$ being produced by the identical double-concave lens. The haptic matching array of Experiments 1 and 2 was covered with foam board, but the same curtain was used to obscure vision for haptic

Table 5

Mean Judged Size (in Centimeters) and Standard Deviations as a Function of Stimulus Standard and Matching Modality and Size (in Centimeters) of the Stimulus Standards in Experiment 4

\begin{tabular}{|c|c|c|c|c|c|c|}
\hline \multirow{4}{*}{$\begin{array}{c}\text { Stimulus } \\
\text { Size }\end{array}$} & \multicolumn{6}{|c|}{ Stimulus Standard and Matching Modality } \\
\hline & \multirow{2}{*}{\multicolumn{2}{|c|}{$\frac{\text { Conflict }}{(\mathrm{vH}-\mathrm{H})}$}} & \multicolumn{4}{|c|}{ Controls } \\
\hline & & & \multicolumn{2}{|c|}{$* \mathrm{H}-\mathrm{H}$} & \multicolumn{2}{|c|}{$\mathrm{v}^{*}-\mathrm{H}$} \\
\hline & $M$ & $S D$ & $M$ & $S D$ & $M$ & $S D$ \\
\hline 4 & 4.65 & 1.51 & 4.95 & 1.48 & 2.59 & 0.86 \\
\hline 5 & 5.97 & 1.57 & 6.49 & 1.48 & 3.48 & 0.95 \\
\hline 6 & 7.52 & 1.50 & 7.90 & 1.47 & 4.53 & 1.59 \\
\hline
\end{tabular}

size judgments. The foam board panel $(76.2 \mathrm{~cm}$ long $\times 11.3 \mathrm{~cm}$ wide) was made as a support for the subjects' hands while they were giving size judgments.

Design and Procedure. The experiment was a between-within design, with one group experiencing a conflict $(\mathrm{vH}-\mathrm{H})$ and with two intramodal groups-a haptic standard group $\left({ }^{*} \mathrm{H}-\mathrm{H}\right)$ and a visual standard group $\left(\mathrm{v}^{*}-\mathrm{H}\right)$. The within-group factors were blocks of trials and stimulus size. In the conflict group ( $\mathrm{vH}-\mathrm{H})$, the subjects examined the stimuli in the presentation box with their right hands while looking at them through the viewing tube. The subjects in the ${ }^{*} \mathrm{H}-\mathrm{H}$ group felt the standard with their right hands. The subjects in the $\mathrm{v}^{*}-\mathrm{H}$ group looked through the viewing tube at the standards.

All the subjects in Experiment 4 were told to judge the true widths of the squares and to give their size estimates by reaching behind the curtain with their left hands and making a pincers posture of the thumb and index finger. The subjects were instructed to maintain the fingers of their left hands in the horizontal plane and to hold their fingers parallel to the front edge of the apparatus for size estimates. In addition, they were asked to keep the hand making size estimates at the body midline as they rested their hands on the foam board panel behind the curtain. The subjects were told to relax their fingers on the foam board between trials. No feedback was given, and size estimates were measured with a ruler (see Heller \& Joyner, 1993, for further details).

The presentation of the three sizes of squares was in random order, but all the subjects started with the 5 -cm square. In all groups, there were five blocks of trials, with each square appearing once in each block in the same random order. There were fewer trial blocks in Experiment 4, since trial block effects in Experiments 1 and 2 seemed most pronounced over the first five blocks of trials (see the SQSF and SQEF curves in Figure 2).

\section{Results and Discussion}

The results of Experiment 4 are shown in Figure 5 and Table 5 and show clear haptic dominance. The subjects tended to overestimate size in the conflict $(\mathrm{vH}-\mathrm{H})$ group $(M=6.0 \mathrm{~cm})$ and in the haptic $\left({ }^{*} \mathrm{H}-\mathrm{H}\right)$ group $(M=$ $6.4 \mathrm{~cm}$ ) but made much smaller size estimates in the 0.5 $\times$ visual $\left(\mathrm{v}^{*}-\mathrm{H}\right)$ group $(M=3.5 \mathrm{~cm})$. The data from the experiment were subjected to a between-within ANOVA, with the three groups as a factor and within-group measures being size and trial block. The effect of group was highly significant $[F(2,27)=13.9, p=.0001]$, and the effect of size was significant $[F(2,54)=244.1, p<.001]$, as were the effect of trial block $[F(4,108)=5.6, p<.001]$ and the two-way interaction between size and trial block $[F(8,216)=2.0, p<.05]$. Size judgments grew smaller over trial block, but not as much for the smallest, $4-\mathrm{cm}$ stimuli. Also, the interaction between group and size was significant $[F(4,54)=4.0, p<.01]$, reflecting the increased effect of group for the larger stimuli. The subjects showed clear reliance on touch, since the haptic intramodal $(* \mathrm{H}-\mathrm{H})$ and the conflict $(\mathrm{vH}-\mathrm{H})$ groups yielded similar mean judgments.

Separate ANOVAs were conducted to compare the conflict $(\mathrm{vH}-\mathrm{H})$ group with the visual standard $\left(\mathrm{v}^{*}-\mathrm{H}\right)$ group and with the haptic standard $\left({ }^{*} \mathrm{H}-\mathrm{H}\right)$ group. The ANOVA comparing the $\mathrm{vH}-\mathrm{H}$ and the ${ }^{*} \mathrm{H}-\mathrm{H}$ groups found a nonsignificant main effect of group $(F<1)$, indicating that the conflict subjects performed like those in 

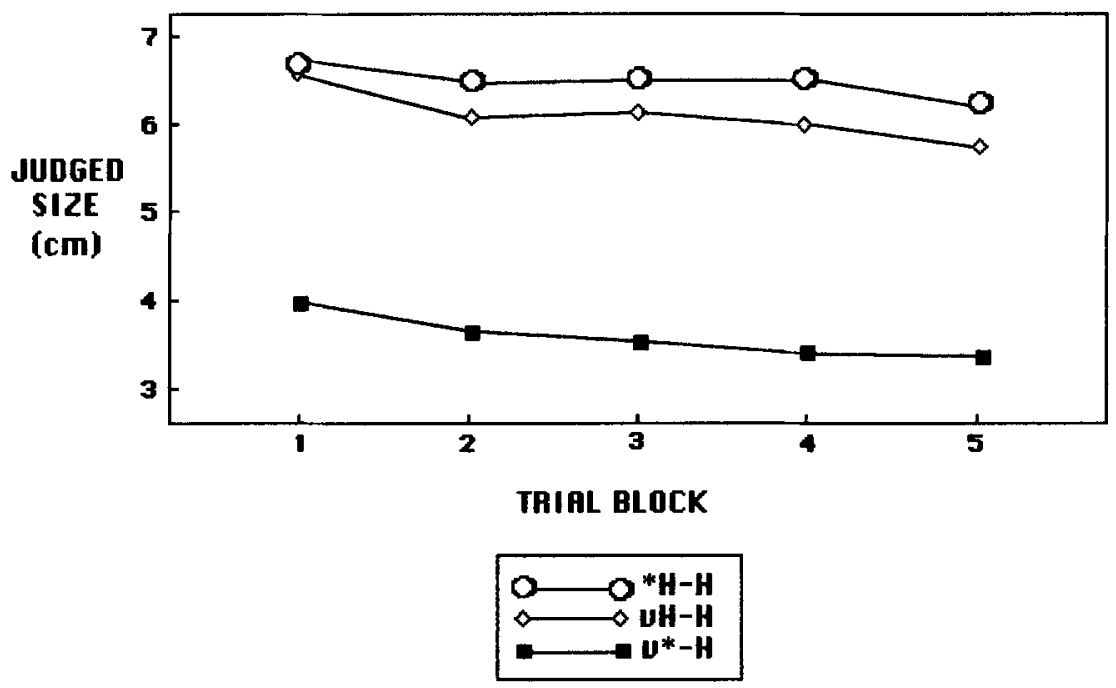

Figure 5. Mean size judgments over trial block, with the data collapsed over size of the standards, in Experiment 4 . All the subjects made size estimates, using a pincers posture of the index finger and thumb of the left hand. Thus, conflict subjects (vH-H) made haptic size estimates, as did the haptic $\left({ }^{*} \mathrm{H}-\mathbf{H}\right)$ and visual controls $\left(\mathbf{v}^{*}-\mathbf{H}\right)$.

the * $\mathrm{H}-\mathrm{H}$ group. A separate ANOVA compared the $\mathrm{vH}-\mathrm{H}$ group with the $\mathrm{v}^{*}-\mathrm{H}$ group and found a highly significant main effect of group $[F(1,18)=18.43, p<.001]$.

It should be noted that the subjects showed haptic dominance on the first block of trials (see Figure 5) and the haptic and conflict groups showed very similar size judgments overall (see Figure 5 and Table 5). Separate analyses were performed on the data for the first block of trials, and the results were consistent with the foregoing analysis (see Figure 5). On the first block of trials, the conflict subjects differed significantly from those in the $\mathrm{v}^{*}-\mathrm{H}$ group $[F(1,18)=14.1, p=.0015]$, whereas the haptic mean $(M=6.58 \mathrm{~cm})$ was almost identical to that for the conflict subjects $(M=6.54 \mathrm{~cm} ; F<1)$. These data differ from those of Hershberger and Misceo (1996), since clear haptic dominance occurred on the first trial and trial block and was not dependent on repeated exposure to the task.

The subjects in Experiment 4 overestimated size when making their size estimates. This overestimation may have derived from the posture they engaged in when reaching behind the curtain with their left hands. Thus, the subjects had to reach in the front of the box to feel the conflict stimuli with their right hands and had to bend over to look down through the viewing tube, while reaching behind the curtain at the top of the apparatus with the left hand. This abnormal posture emphasized the involvement of the arm/shoulder movement space and could help to explain the general overestimation of size (see Heller, Calcaterra, Burson, \& Green, 1997).

There is an alternative interpretation of the obtained overestimation that should be considered. When people normally grasp an object, they first open their fingers too wide and then bring them together to enfold the object. Perhaps the obtained overestimation in the pincer's posture measurement derived from the first stage of this two-stage sequence for actually grasping objects. Thus, the subjects may have carried over this aspect of preparation for actually picking up an object to the present task demanding perceptual judgments of object size.

It should be noted that the conflict subjects in Experiment 4 did not spontaneously adopt the measuring strategies that were obvious in Experiments 1 and 3. The subjects in Experiment 4 used a grasping pincers posture of the fingers of the right hand and did not lay their fingers across the standard stimuli, as did some of the subjects in the earlier experiments. Also, 2 subjects in Experiment 4 noticed the effect of the lens, but not on the first trial. One noticed that the stimuli felt larger after the first two squares, and 1 noticed the lens on the second trial.

\section{GENERAL DISCUSSION}

The subjects in Experiment 1 did not show dominance of one modality over the other in conflict conditions. Thus, they showed mean size matches that were approximately midway between those for vision and touch. However, in Experiment 2, it was found that unobstructed sight of one's minified hand tends to increase the magnitude of size estimates. This needs to be considered in the evaluation of experiments that allow subjects visual information about hand size in discrepancy conditions, especially when the discrepancy is induced by a lens. Experiment 3 yielded visual dominance when subjects were required to make absolute metric size judgments, using sight of a ruler. These results were similar to those previously reported by Hershberger and Misceo (1996). Finally, the subjects showed clear reliance on touch in Experiment 4, when they estimated size with a pincers posture of the index finger and thumb. Haptic dominance was obtained when the subjects were able to provide rapid, facile size 
estimates, using touch. This suggests that prior demonstrations of visual dominance (e.g., Rock \& Victor, 1964) may be limited to the matching or drawing conditions of their experimental paradigm. Thus, procedural variations can sometimes give the appearance of visual dominance, when that is, instead, a consequence of biasing subjects by requiring visual judgments or of overloading the attentional capabilities of touch.

It is not appropriate to assume that when vision and touch convey conflicting information about length, people will tend to rely on visual information (see, e.g., D. H. Warren \& Rossano, 1991, p. 123). This is a blanket overgeneralization and does not do justice to the evidence. People may shift their reliance to either vision or touch, depending on a variety of circumstances. Allowing sight of the hand and rapid tactual judgments will tend to shift the balance toward touch.

The conflict procedures involving matching responses yield questionable data. The presence of a conflict requires that subjects actually register haptic size, and that is doubtful in matching paradigms. The matching procedure imposes a memory burden on touch, given sequential matching. When simultaneous matching is used, subjects are required to integrate information between the hands and to control movement in two hands at once. When one limits exploratory strategies to a grasp (as in Hershberger \& Misceo, 1996; Rock \& Victor, 1964), researchers may not discover that subjects have some difficulty estimating size haptically and that they will attempt to use alternative methods.

\section{Sight of Hand}

Sight of the hand has an influence on subjects, as was indicated by the results of Experiment 2. Sight of the bare hand during discrepancy conditions altered size judgments and probably helped to promote haptic dominance in Experiment 4 . However, although some subjects were aware of the discrepancy, most clearly were not aware. Furthermore, even when some subjects became aware of the discrepancy and the manipulation of vision, this typically occurred during the first trial block, and not much later on. This effectively rules out adaptation to the lens as an explanation of the data and also makes it unlikely that touch generally becomes more potent over trials.

The use of a cloth to cover the fingers was an important procedural manipulation in most earlier research. The aim was to keep subjects from noticing the distorting effects of the lens on size or shape. Rock (Rock \& Victor, 1964) tried to prevent conscious awareness of the lens by limiting subjects to one trial. Hershberger and Misceo's (1996) subjects could simply have become aware of the distorting effect of the lens over blocks of trials as the subjects saw their fingers move beneath the cloth. This awareness of the conflict could have yielded a higher order cognitive judgment, rather than an immediate perceptual response to the discrepancy. This interpretation of the data is supported by the lack of a trial block effect in most of the experiments reported here. The haptic dominance in Experiment 4 was shown on the first trial block.
The normal state of affairs is for the senses to work cooperatively. Visual dominance over touch is found under very contrived laboratory circumstances, with reduced information. That is, visual dominance is obtained when we make it difficult for subjects to perceive the normal distance relations of objects and sight of the hands is distorted by lenses. Note that it is strange for people to ever say that they are not clear how far their hands are from their faces, but they did this in conflict conditions in the reported experiments. Some subjects said that they thought that object distance was changing. This meant that the experimental arrangement and visual information induced an inability in some of the subjects to make judgments about arm and hand position.

The subjects' references to changes in perceived distance is reminiscent of R. M. Warren's $(1981,1983)$ physical correlate theory and is consistent with that theoretical formulation. Warren proposed that subjects will often bring their tacit knowledge about the relationship between physical distance and perceived brightness and loudness to the laboratory. Thus, our knowledge of the relationship between distance and motor activity is necessary for functioning in the world and must undergo continual calibration (R. M. Warren, 1983). On this view, subjects may perceive a dim light as bright when it is perceived as being far away. Some of the subjects in conflict conditions in the present experiments may have visually perceived the squares as being too far away and, therefore, judged them to be as large as they felt.

One might argue that allowing subjects the opportunity to view their hands as they touched the squares compromised the effectiveness of the manipulations in the experiments reported here. However, it would be possible to argue, in reply, that feeling an object through cloth, as in the experiments by Rock and Victor (1964) or Hershberger and Misceo (1996), could also bias subjects against touch. The use of a cloth between the stimuli and the subjects' hands can alter the sense of touch and, perhaps, make it less reliable. Certainly, the procedure has the potential of biasing subjects against their sense of touch by blurring tactual sensations and making them less distinct. Blurring sight generated reliance on touch, given a conflict between the senses (Heller, 1983). Although the use of a cloth did not eliminate the influence of touch in Hershberger and Misceo's experiments, the procedure might have reduced the reliance on touch. In other, very different circumstances, of course, an intervening cloth may actually help perception (see Katz, 1989, pp. 10-11).

\section{Individual Differences}

One reviewer noted that the method of averaging data obscures individual differences. Thus, individual subjects may have relied on touch or vision, and this would not be apparent when examining mean scores. The data of Experiments 1, 3, and 4 were reanalyzed to examine individual subject scores. An overall mean score was computed for each subject. Then the score was compared with the mean of the scores for the visual and the haptic comparison groups. Scores that were smaller than the 
overall mean for the intramodal, comparison groups were regarded as relying on vision, whereas larger scores were identified as relying on touch. For example, this method evaluates whether the $\mathrm{vH}-\mathrm{V}$ and $\mathrm{vH}-\mathrm{H}$ estimates differed from the average control compromise in Experiment 1 $\left[\left({ }^{*} \mathrm{H} \mathrm{H}+\mathrm{v}^{*}-\mathrm{V}\right) / 2\right]$. Overall in Experiment 1 , for the $\mathrm{vH}-\mathrm{V}$ group, 6 subjects relied on touch, and 4 showed visual dominance. On the first trial block, half of the subjects in that group showed visual dominance, and half showed haptic dominance. Six of the $\mathrm{vH}-\mathrm{H}$ subjects showed haptic dominance, only 3 relied on vision, and 1 showed equal reliance on vision and on touch. On the first block of trials, 6 subjects showed haptic dominance, and 4 relied on vision. Most of the subjects had scores that were close to the mean of the two control groups, with the exception of 1 subject in each group, who showed extreme haptic dominance.

In Experiment 3, which used absolute visual metric judgments, 9 subjects showed visual dominance overall, whereas 1 relied on touch. On Trial Block 1, 8 of the subjects showed visual dominance. Again, all of the subjects had mean scores that were close to the means of the control groups. The data of Experiment 4 also yielded little evidence of individual differences. While 9 of the subjects showed haptic dominance overall, 1 relied on vision. Even on the first block of trials, 7 subjects showed haptic dominance, with 3 relying on vision. Two of these subjects showing reliance on sight had scores that were close to the overall mean, but 1 was strongly swayed by visual input.

\section{Conclusions}

Taken together, the results of the present experiments suggest that subjects do not invariably show visual dominance when exposed to a discrepancy between vision and touch, a result that is consistent with Hershberger and Misceo (1996). However, the study also found that dominance relations vary with the speed and precision of the response measure and modality and that there are circumstances that promote reliance on touch or on vision.

Statements about intersensory dominance are often oversimplifications of a very complex process. It may be important to distinguish between a sense's attracting one's attention and its having the power of acting as the dominant sense, given a discrepancy. For example, audition is very attention demanding, but vision is dominant over audition in judgments of spatial location. The relationships between vision and touch are not this simple, since touch and vision have multiple roles, involving affect, spatial cognition, and guidance.

\section{REFERENCES}

Abravanel, E. (1971). The synthesis of length within and between perceptual systems. Perception \& Psychophysics, 9, 327-328.

ABRAVANEL, E. (1973). Retention of shape information under haptic or visual acquisition. Perceptual \& Motor Skills, 36, 683-690.

BARTLEY, S. H. (1953). The perception of size or distance based on tactile and kinesthetic data. Journal of Psychology, 36, 401-408.
CASHDAN, S. (1968). Visual and haptic form discriminatıon under conditions of successive stimulation. Journal of Experimental Psychology, 76, 215-218.

Cashdan, S., \& Zung, B. J. (1970). Effect of sensory modality and delay on form recognition. Journal of Experimental Psychology, 86, 458-460.

FrEIDEs, D. (1974). Human information processing and sensory modality: Cross-modal functions, information complexity, memory, and deficit. Psychological Bulletin, 81, 284-310.

FreIDES, D. (1975). Information complexity and cross-modal functions. British Journal of Psychology, 66, 283-287.

Gentilucci, M., Daprati, E., Toni, I., Chieffi, S., \& Saetti, M. C. (1995). Unconscious updating of grasp motor program. Experimental Brain Research, 105, 291-303.

HEL.LER, M. A. (1982). Visual and tactual texture perception' Intersensory cooperation. Perception \& Psychophysics, 31, 339-344.

HeLler, M. A. (1983). Haptic dominance in form perception with blurred vision. Perception, 12, 607-613.

Heller, M. A. (1985). Effect of magnification on texture perception. Perceptual \& Motor Skills, 61, 1242.

Hel Ler, M. A. (1989). Texture perception in sighted and blınd observers. Perception \& Psychophysics, 45, 49-54.

Heller, M. A. (1992). "Haptic dominance" in form perception: Vision versus proprioception. Perception, 21, 655-660.

HELLER, M. A. (1993). Influence of visual guidance on braille recognition: Low lighting also helps touch. Perception \& Psychophysics, 54, 675-681.

Heller, M. A., Calcaterra, J. A., Burson, L. L., \& Green, S. L. (1997). The tactual horizontal-vertical illusion depends on radial motion of the entıre arm. Perception \& Psychophysics, 59, 1297-1311.

Heller, M. A., \& Joyner, T. D. (1993). Mechanisms in the haptic horizontal-vertical illusion: Evidence from sighted and blind subjects. Perception \& Psychophvsics, 53, 422-428.

HershberGer, W. A., \& MisceO, G. F. (1996). Touch dominates haptic estımates of discordant visual-haptic size. Perception \& Psychophysics, 58, 1124-1132.

KATZ, D. (1989). The world of touch (L. E. Krueger, Trans.). Hillsdale, NJ: Erlbaum

Lederman, S. J., \& Abbott, S. G. (1981). Texture perception: Studies of intersensory organization using a discrepancy paradigm and visual vs. tactual psychophysics. Journal of Experimental Psychology Human Perception \& Performance, 7, 902-915.

POWER, R. P. (1980). The dominance of touch by vision: Sometımes incomplete. Perception, 9, 457-466.

Power, R. P. (1981). The domınance of touch by vision: Occurs with familiar objects. Perception, 10, 29-33.

Rock, I., \& HaRris, C. S. (1967). Vision and touch. Scientific American, 216(5), 96-104.

Rock, I., \& Victor, J. (1964). Vision and touch: An experimentally created conflict between the two senses. Science, 143, 594-596.

RYAN, T. A. (1940). Interrelations of the sensory systems in perception. Psychological Bulletin, 37, 659-698.

Schlater, J. A., Baker, A H., \& Wapner, S. (1981). Apparent arm length with active vs. passive touch Bulletin of the Psychonomic Society, 18, 151-154

Teghtsoonian, R., \& Teghtsoonian, M. (1970). Two varieties of perceived length. Perception \& Psychophysics, 8, 389-392.

WARREN, D. H., \& RosSANo, M. J. (1991). Intermodality relations: Vision and touch. In M. Heller \& W. Schiff (Eds.), The psychology of touch (pp. 119-137). Hillsdale, NJ· Erlbaum.

WARREN, R. M. (1981). Measurement of sensory intensity. Behavioral \& Brain Sciences, 4, 175-223.

WARREN, R. M. (1983). The calibration of sensory scales. Behavioral \& Brain Sciences, 6, 319-320.

Zung, B. J., Butter, E. J., \& Cashdan, S. (1974). Visual haptic form recognition with task delay and sequenced bimodal input. Neuropsychologia, 12, 73-81.

(Manuscript received May 19, 1997; revision accepted for publication July 17, 1998.) 